\title{
Millikan-Teacher and Friend*
}

\author{
H. V. NEHER \\ California Institute of Technology, Pasadena, Calffornia
}

(Received 24 July 1964)

\begin{abstract}
Editors Note: As a result of support by Addison-Wesley Publishing Company, the American Association of Physics Teachers has established an annual lectureship, named in honor of Robert A. Millikan. It is anticipated that this will bring to each summer meeting of the Association a physicist who will speak on a topic of current interest and that the summer meeting will thus have a feature comparable with the Richtmyer Lecture at the annual meeting. The committee responsible for the first Millikan Lecture chose H. V. Neher, long time associate of Millikan. This highly suitable choice was as appropriate as was Neher's choice of a topic-Millikan himself. 'The editors of the American Journal of Physics are grateful for permission to publish this pleasantly informal biographical lecture, spiced as it is with personal reminiscences.
\end{abstract}

$I_{\text {ats }}^{1}$ FEEL particularly honored to have been asked by the American Association of Physics Teachers to give the first of the newly established "Millikan Lectures." These lectures will do much to keep alive the memory of this most remarkable person, in particular to re-acquaint physics teachers with his ideas on pedagogy and his contributions to the teaching of physics both in the high schools of the country and in the colleges and universities.

This association of physics teachers recognized the contributions that Millikan made to the teaching of physics by presenting to him, in December 1940, its fifth Oersted Medal.

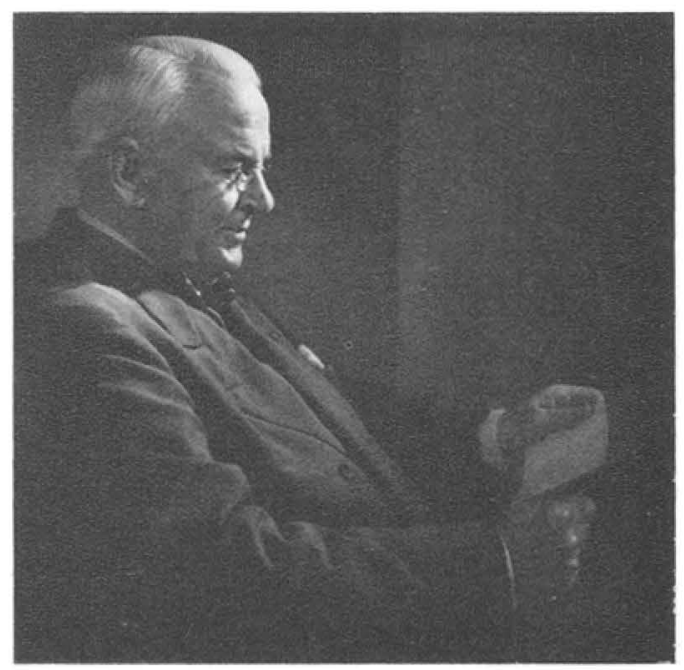

FIG. 1. Robert Andrews Millikan (1868-1953).

* Delivered at the meeting of the American Association of Physics Teachers, University of Wisconsin, Madison, Wisconsin, 19 June 1964.
I suspect that no one individual has had such a profound and lasting influence on physics in this country as did Millikan. This influence took three distinct forms. First, was the direct influence through his writing of textbooks, originally for colleges and universities, and later for high schools. Second, was his direct contact with students in teaching and devising experiments for the laboratory. Third, was his contact with graduate students and the profound influence he had on their careers, whether they went into industrial laboratories, or into teaching.

What I will have to say will be based largely on my own, personal recollections. I hope you will pardon me if I reminisce a bit. Actually I was the audience of one for much of what appears in his autobiography, ${ }^{1}$ for on the several long trips we made together, he would often launch into long accounts of his past experiences.

Perhaps more than any other person he can be considered the father of physics in this country. The period which his life spanned, from 1868 to 1953 , was unique in the development of knowledge, both technical and scientific, of the physical world. Physics really grew up and became adult in this interval.

Let me begin by relating the several facets of an individual's life that Millikan considered important when considering additions to the Caltech staff. In order of importance he would take into account, (1) their research ability, (2) their teaching ability, and (3) their interest in outside affairs. He himself exemplified all three

1 R. A. Millikan, The Autobiography of Robert A. Millikan (Prentice-Hall Inc., Englewood Cliffs, New Jersey, 1950). 
of these to a high degree. In the early years of his life at the University of Chicago he was engaged in writing physics textbooks and in teaching. In his writing he was highly successful, for the country was only then becoming awakened to the increasing need of physics in its schools. Millikan did much to hasten that awakening.

One of his earliest attempts to contribute to the textbook field was the translation from German into English of that excellent book of Drude, Theory of Optics. This he did with the help of Mann. As Millikan said, he knew some German and Mann knew how to run the typewriter. This translation appeared in 1902. This book was really an expression of von Helmholtz's lectures, for Drude was one of his students.

By its nature, Drude's Optics never sold many copies and Millikan reckoned his monetary return at only a few cents an hour, but he considered his time well spent, nevertheless.

Being an experimentalist himself and realizing the great value of learning physics by handling equipment, he laid great stress on laboratory. Those of you who know his books, even the last of the line, by Millikan, Roller, and Watson, know how closely the text is tied to experiment. These books have directions for doing an experiment at the end of each chapter: The text and problems go into the details and ramifications of the particular physical principles that are covered by the experiment.

His textbooks were not encyclopedic. The material covered was fundamental. The books adhered to the physical principles and did not get sidetracked into the engineering aspects.

Just as automobiles get bigger to meet a supposed popular demand, until they get so big they become ridiculous and then we start over again, so textbooks go through a similar cycle. Millikan's Mechanics, Molecular Physics and Heat was the Volkswagen of its time. Since then we have seen numerous body styles, interior decorations, doodads and accoutrements, together with various paint jobs. Somehow our students have managed to learn some physics, irrespective of what style textbook they used. The most important ingredient that goes into a physics course is probably not the particular book used, but is a steep function of those indefinable characteristics that go into what we all know as a good teacher.
The first ten years of his career at the University of Chicago were largely taken up with teaching and textbook writing. Returns from his book had begun to come in, but he felt that he was not coming to grips with his chief love--. doing research. He had, from 1896 to 1906 , written three minor scientific papers but had really not hit his stride. In 1907, when the writing of the Millikan and Mills text had been completed, he "kissed textbook writing goodbye, at least for the present, and started intensively into the new problem ....," the problem that later was solved so beautifully and became known all over the world as the Millikan Oil-Drop Experiment. The work on this problem led to many ramifications, both theoretical and experimental. His insistence that his oil drops always carried an integral number of unit charges, the charge of the electron, soon convinced most people that he was correct. The one person who held out the longest, that there were smaller charges than Millikan's unit charge, was Ehrenhaft, with whom Millikan had a running verbal battle for a good many years. It is of some interest that the size of the electronic charge has recently come up again for consideration. Theorists like Gell-Mann are now predicting, that under certain conditions, charges which have been named "Quarks," smaller than the electronic charge, should occur. I might add that, so far as I know, no such particles have as yet been found, so that Millikan's unit electronic charge may still be the smallest that occurs in nature.

We are not here concerned directly with the research work of Dr. Millikan. His teaching and his research were, however, intimately interrelated so that we must mention some of the characteristics that also made him a first-rate research man. I will list them, as I see them, as follows : First, he kept abreast of what was going on in other research laboratories. His personal acquaintance with what was being done in Germany began in 1895 . He spent an exciting 15 months there, visiting laboratories, talking with people and doing some research. He returned to Europe many times in subsequent years, always searching out and talking with the people who were in the vanguard of research work. Further, he read a great deal. Physics was always exciting, perhaps more so because he often found so little 
time to spend on it due to his other duties. During his travels (and he averaged about five times a year to the East coast of the U.S.) he always took along a pile of reading material such as science abstracts, reprints, periodicals and books. He read "Science Abstracts," faithfully, to keep posted on what others were doing. The second characteristic was that he had an inquiring mind. $\mathrm{He}$ felt that the workings of nature could be understood, that there was much to understand, and he was determined to find out as much as he could. Third, he had developed a keen sense of the way nature behaved. While others used analytical methods and fancy mathematics, Millikan had a feeling for the physics involved, stripped of all the trappings. As a result of the above qualities, he had developed a sense of what were the important problems to work on. He started on the problem of finding the charge of the electron because he sensed that here was something important. He made progress because he followed the leads. In the case of the photoelectric effect, he again sensed that here there was something important and pursued the leads until he had everything under control and had arrived at a final, important result. Many of his investigations grew out of others. For example, in trying to pull electrons out of metals, he saw that the vacuum hot spark that occurred at high-field strengths would be a means of stripping atoms of their electrons, and this all led to the very fruitful field of extreme ultra-violet spectroscopy.

Millikan had a sense for what was important in fields other than physics. A good illustration was his interest in seeing that astronomy was pushed at California Institute of Technology. The same applied to other fields, such as biology. It was, of course, Hale's idea to make a 200-in. telescope, but is was Millikan who really gave the project the push that was needed. It was Millikan who sold the project to the various members of the Rockefeller General Education Board.

He was extremely anxious that the new California Institute of Technology become an asset to the local community, and it was primarily Southern California that he had in mind when he tried to build an engincering and science school in Pasadena. He knew that if he could sell his ideas to the local community he would get its support. He has been critized by some for the methods he used in the twenties and thirties to raise funds, and some have accused him of seeking publicity. I suppose everyone who tries to get things done and by nature has a strong, outgoing personality, is bound to antagonize some people. This seems to be inevitable. It is the person who can rise above such criticism and the pettiness of little men, who succeeds. I knew Millikan intimately from 1932 on. I never knew him to seek publicity. The publicity and press agents sought him. Likewise, I never knew him to take credit for a discovery that was made by someone else. It is true that he often had occasion to talk about what others had done, especially what had been done by the workers at the Institute and he never played down such accomplishments. But he always insisted that the individual publish his own discovery.

But interest people in Caltech he did, and he accomplished more in twenty years than many institutions accomplish in a hundred. He was, by nature, an optimist. Anyone who was not would certainly have floundered in the early years of the great depression. Caltech, like many schools, was hard hit, but with the sacrifices of many people, survived the storm. In these years, the whole of the cosmic-ray work at the Institute was carried on under a Carnegie Corporation grant of $\$ 15000$ a year.

I am sure that Millikan would have subscribed to the philosophy contained in the following quotation: (source unknown). "The rains that nourish the optimist's flowers, make the pessimist's weeds grow. And the drought, that does what the pessimist predicted for the flowers, does what the optimist hoped for the weeds."

Concerning the educational policies of the Institute, these were established early, soon after Millikan took over in 1921, and most of them have remained. One policy that should be mentioned was his emphasis on the humanities. He had broad interests himself and wanted the scientists and engineers that came out of Caltech to have that broad training that would fit them for the most useful lives in the community in which they would live. Dr. Noyes was also of the same mind. Thus, approximately one-fourth of the work an undergraduate takes, then as well as now, is in the humanities. Another policy, which has been maintained, is to have a close relation- 
FIG. 2. Persomel at the Norman Bridge Laboratory of Physics, 1923. In the front row, from left to right are E. C. Watson, R. C. Tolman, Harry Bateman, Charles Darwin, R. A. Millikan, A. Sommerfeld, Paul S. Epstein, and L. H. Gilmore.

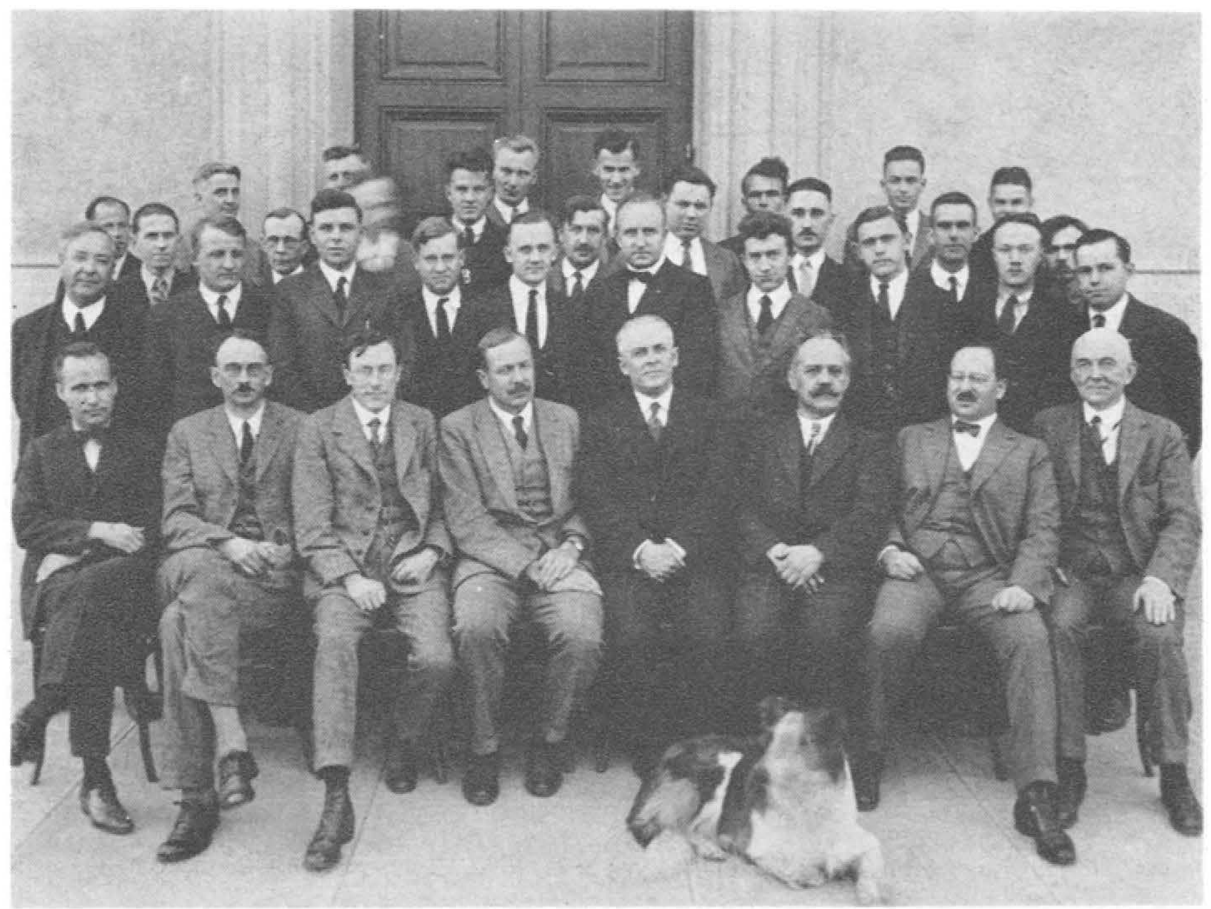

ship between the sciences and engineering. For many years, physics, mathematics and electrical engineering were in the same department. Electrical engineering, in recent years, has broken away and its place has been taken by astrophysics, but this does not keep many of the E. E. staff from attending physics seminars.

When we describe Millikan as a teacher, we must not only think of his direct contact with students, but also with those broad policies that had so much to do with the professional lives of students. I have in mind the bringing to Caltech of notable people in physics to visit, and in many cases give lectures. To name them all would be essentially to name all the important physicists of the time. Dr. H. A. Lorentz was in residence on two different occasions. Some of the others were Sir C. V. Raman, Dr. Charles Darwin, Dr. Paul Ehrenfest, Dr. Arnold Sommerfeld, Dr. Albert Einstein and many others. To those of us who were graduate students or young members of the staff at that time, being able to hear and in some cases to get acquainted with men of this stature, made these memorable years and they had a deep influence on our professional careers.

Millikan also knew that a research and teaching institution is not just buildings. The most important ingredient, as we all know, is a competent staff. I will only name a few of those men whom Millikan attracted to the various departments at C.I.T. There was Morgan in biology, von Karman in aerodynamics, Gutenberg in geophysics, Tolman in physics and chemistry, Bateman in mathematical physics, Pauling in chemistry, Epstein in theoretical physics, etc.

In Fig. 2 a photograph taken of the personnel in Bridge Laboratory in 1923, is reproduced. The chief visitors from Europe at this time were Charles Darwin and Arnold Sommerfeld. Similar photographs taken in other years show such visitors as H. A. Lorentz or Albert Einstein.

I suppose one of the most important influences on the exact sciences in this country was the establishment of the National Research Fellowships. The history of these Fellowships is briefly as follows: Ten months before World War I had ended, Mr. Vincent, President of the Rockefeller Foundation, wrote Millikan, proposing that a national research institute in physics and chemistry be established where fundamental research in these fields, that had shown themselves to be of such importance in the war effort, could be carried on. Millikan was sure that this was not the way to get research work done. He made a 
counter suggestion that the Rockefeller money be put into post-doctoral fellowships. In the words of Millikan to Vincent, "My own judgment is that if you have a certain amount of money to put into this process of stimulation you will ultimately get a very much larger return from your available philanthropic funds if you utilize existing plants and put all your new funds into actually supporting in them, new research projects with new personnel, if necessary, so as effectively to transform them into new research institutes in physics and chemistry. Again, this latter procedure is a vastly more effective one for stimulating local pride and the consequent flow of new funds from local sources into the new developments." There seems to be little doubt that Millikan's judgment was correct and that these fellowships had, between the two world wars, a profound effect upon the speed with which the natural sciences developed in this country.

Let us now look at some of the other aspects of Millikan's career that characterized him as a good teacher. To give you an insight into the ideas he held about teaching, let me quote to you a few sentences from Millikan's reply to the presentation of the Oersted Medal. ${ }^{2}$ His address is entitled, "The Opportunity of the Physics Teacher." In this speech he said, "The most important job of the teacher is to know his students, every one of them, so that he will make as few mistakes as possible in rating their qualities and their capacities justly and accurately in order that he may steer them wisely. Talking entertainingly to a hundred or two hundred students is a wholly subordinate and trivial requirement of a good teacher. The great, indispensable requisite is conscientiousness in watching carefully and discriminatingly the way his students solve problems, the way they answer examination questions, the way they pose questions of their own. This job cannot be delegated to anyone else without abdicating the main job of the teacher.

"Such abdication may sometimes be necessary when the exigencies of the whole educational machinery require a teacher to change his job and become an administrator instead of a teacher, but even so, it is of the utmost impor- tance for the administrator, in performing his new function of selecting good teachers to know what the prime requirement of a good teacher is, namely, conscientiousness in doing the job of selection and vocational guidance as well as it can be done. No professional guidance person can do that. It is the teacher's own job." This then gives briefly, in Millikan's own words, what he regarded as the chief function of a good teacher.

According to this definition of what makes a good teacher, Millikan would have ranked at the top of the list. Witness the large number of physicists who have been or who now are holding top positions in academic institutions or in industry who knew him affectionately as "The Chief" and who were well known by him as students and were guided in those years by his sound judgment and advice.

'Those who knew "The Chief" will all agree, I think, that he was not a polished lecturer. He did not believe in the large lecture classes that he had seen in Europe. Also, he himself would not have been the person to give such lectures. He was more in his element with a small class. This is where his contagious enthusiam and his warm personality were the most effective.

More effective still were these qualities when just individuals were involved. Millikan had a personality that attracted many people, including, of course, graduate students and those who worked with him. During the nineteen twenties and early thirties, he directed and worked closely with graduate students at Caltech. For many years he taught one term of a graduate course called Atomic Physics which all first year graduate students took. The chief purpose of the course was to give Millikan a chance to become acquainted with each student. He carefully watched their performance in class and the way they answered questions on examinations, which he read with great care. On the basis of these he formed his judgment of the competence of each student. Sometimes, this judgment turned out not to be sound, but this was the rare case. In general, he was right. As Director of the Norman Bridge Laboratory, he would assign students to research problems according to how he judged their potentialities. In those days very few graduate students went into theoretical 
physics. Millikan used to say that the proper ratio of theorists to experimentalists was 1 to 10 . This situation has changed considerably since that time. About 60 percent of the present applicants for graduate work at Caltech want to go into theoretical physics.

The times remembered mostly in those graduate years were the occasions when The Chief would drop into the room of a graduate student to chat. These occasions were rare when I first went to Caltech in 1928 and became rarer in the life of the usual inhabitant of Bridge Lab as time went on. It is perhaps a wonder that he gave as much time as he did in talking with graduate students. He was not only Director of the Norman Bridge Laboratory, but he was also Chairman of the Executive Council, which to all practical purposes, amounted to being President of the Institute. The late nineteen twenties and the ninteen thirties were times of stress as well as of growth of the Institute so that the burdens of administration and money raising were heavy.

One of the roles Millikan assumed for many years was arranging for most of the speakers of the general physics seminar. During most of the time this seminar met twice a week. It is of interest that all through the Second World War, he insisted on running this seminar, "Because," he said, "we must not let the interest in physics as such, die." I might add that he never missed a seminar if it was at all possible for him to be there. I recall several occasions when we were out on local field trips, when it would have been so easy to have played the truant. But his conscience would not allow such liberties.

Speaking of liberties, he had the following definition of a Puritan conscience. "A Puritan conscience," he said, "is one that does not keep you from sinning, but does keep you from enjoying it when you do sin."

Not until a year following the receiving of my Ph.D. degree did my association with Millikan become more than casual. It was a day in February of 1932, while J. was a research fellow, that he and Dr. Ira Bowen came into my room and asked if $I$ would like to work with them on some cosmic-ray problems. Thus began an association which lasted for over twenty years and which I regard as one of the most important things that could happen to any person. I recall the long hours we would spend together discussing cosmic rays or some other topic. Often these get-togethers would occur after he could get away from some social function. He would say, "I'll see you in your room tonight at 10 o'clock." Usually it would be 11 o'clock or later before he would show up, but show up he would and then would talk until 1 or 2 in the morning. I often wondered how he could spare all this time, because these occasions were fairly common. Also, if I were to go to see him in his office during the day, he would sometimes talk for several hours at a time. Very seldom did he seem to be in a hurry and nearly always he had time to talk and listen.

I remember one occasion in particular, not long: after he had asked me if I wanted to work with him. We had decided to build a self-recording ionization chamber that would be insensitive to vibration and tilt. The purpose was to send these instruments to high altitudes in airplanes at various latitudes to make measurements on cosmic rays. The construction involved the making of a suitable quartz system that would be sealed inside a pressurized sphere. To make the instrument insensitive to tilt a taut quartz fiber was used with a balanced cross-arm. My skill at such things was none too good, and I had been having a series of breakages and other bad luck. Contributing to the distress was a dead-line to commence making airplane flights at March Field, Calif. General (Hap) Arnold (then Colonel Arnold) was in command of the field at this time. I finally went to Dr. Millikan's office one day and told him my woes. His sympathy and understanding did much to revive my sagging spirits, and it was not long after this that lady luck smiled that sweet smile.

These cosmic-ray expeditions led to many parts of the world. On three occasions we went to Canada together, three times to the midwestern states, once to Mexico and once to India. Such trips gave an unparalleled opportunity to learn to know this person and to learn from him. He had very wide interests, just as his acquaintanceships and friends represented wide interests. While riding in our cosmic-ray truck through Mexico he might discuss the Huntington Library, of which he was one of the directors for many years. Or, he would discuss Gibbon's, "Decline 
and Fall of the Roman Empire," or he might recall his experiences during World War I and the roles played by the various people involved. In traveling through India he liked to talk about the British Empire and what it had done for India. Incidentally, he could not understand why India wanted its independence. Wasn't she far better off under British rule than she would be under her own? He could not understand the attitude of the Indians who shouted, "It isn't a question of good rule, it's a question of who rules." Or, while strolling through the zoological gardens at Singapore, he asked, "Who were the intellectual giants of the 19th century?" $\mathrm{He}$ would begin naming them one at a time, together with what each contributed. Most of these would be physicists like Maxwell and Helmholtz, but he would also name those in other fields like Pasteur. He believed with Pasteur that, "Chance favors the mind that is prepared."

It was on such an occasion, as I recall, that I picked up the quotation, which went something like this; "If I have seen farther than some men, it is because I have stood on the shoulders of those who have gone before." My memory is that this was attributed to Newton, but I have been unable to verify this.

What I am trying to say is, that on many an occasion, Millikan was the Mark Hopkins and I was the James Garfield; he on one end of that famous bench, and I on the other; he was the true teacher, I was the student.

Let me take a short interlude here to relate an incident that does not have much bearing one way or another on the main subject, but which has some interest, perhaps, in itself.

On our way to India, in the fall of 1939 , we found ourselves stranded in Singapore. There were four of us, Dr. and Mrs. Millikan, Dr. W. H. Pickering and myself. We were stranded because the war had broken out and the British had commandeered the ship which we originally booked to take us from Singapore to Calcutta. We finally got passage on a coastwise, coalburning steamer whose captain was a Scotsman of no small proportions. He had been through World War I and had learned some lessons, he said. One was that the enemy had more intelligence than they had been given credit for.
On arriving at Rangoon we were met at the ship by friends, the D. C. Smiths, who were connected with Judson College. They invited us to stay with them which we were glad to do, but we could not get an exact sailing time from the captain. The most he would say was that he was leaving the next day. The Smiths drove us around to see the sights. We drove up the road toward Mandalay and learned that this is not where the flying fishes play and that Old China is not across the bay. Kipling took poetic liberties on more than one occasion.

We learned at $7: 45$ the next morning at breakfast that our boat was sailing at $8 \mathrm{a} . \mathrm{m}$. We were about 6 miles from the wharf. There was no freeway or turnpike, rather the streets of Rangoon are filled with chickens, dogs, priests, bullock carts, and people. We managed to miss them all, arriving at the wharf at 8:05. As we came into view of the ship we saw a line of about 12 coolies who had our luggage on their heads and were headed for the nearby godown. Bill Pickering jumped from our car before it had stopped, ran to the head man of the line and turned him around. The others followed in a follow-theleader hairpin turn. The last coolie carried in his hand, with his arm extended, the last thing he had picked up, Millikan's tooth brush.

A sketch of Millikan would not be complete without mentioning his wife and companion, Greta Millikan. There is no doubt that a woman of less stamina, less sense of humor, less all around capabilities, might have broken under the strenuous life they led. But she managed and managed well. The Millikans did a lot of entertaining, not only of students and faculty but of visitors and friends from all over the world. I shall not attempt to enumerate those I had the privilege of meeting at their home, but their friends included not only physicists but such people as Herbert Hoover, also.

Mrs. Millikan had a keen sense of humor and delighted in telling stories. These, she would spring at unexpected times, but they would usually fit into the conversation. Let me repeat some of these as I recall them. In this year of 1964 in celebrating the 400th anniversary of Shakespeare's birth, the following little ditty is 
appropriate :

$$
\begin{aligned}
& \text { Romeo and Juliet, } \\
& \text { T'was in the restaurant they met } \\
& \text { T'was there that Romeo went in debt, } \\
& \text { For Romeo 'd what Julie -et. }
\end{aligned}
$$

In the days before Pasadena built an auditorium, the community dances were held on the tennis courts in Tournament Park, across the street from Caltech. The sponsoring committee had made certain rules of conduct that the young people were supposed to follow. One rule prohibited young couples from sitting out in parked cars. To enforce the ruling, several spinster ladies would patrol the area. One evening one of the ladies came up to a car where a young couple were all wrapped up in each other in the front seat. "What do you suppose your mother would say if she saw you like this," said the lady to the girl. "I don't know," replied the girl. "You might ask her. She's in the back seat."

A final example of Mrs. Millikan's enjoyment of a story concerns some remarks of Russell Porter. Some of you may remember him. He was an artist, architect, amateur astronomer, composer and arcitic explorer. Among other things he designed the 200-in. telescope dome and building on Palomar and made the detailed pencil sketches of the 200 -in. telescope that now hang in the Robinson Astrophysics Laboratory at Caltech. Concerning his Artic experiences, he knew both Cook and Peary very well, having been on expeditions with each of them. As is now well known, Cook for a while successfully claimed that he had been to the north pole before Peary, but later he was discredited. Porter's comment, in comparing the two men, was, "Cook was a gentleman and a liar; Peary was neither."

Perhaps some of Millikan's personal characteristics will be of interest. He loved to relate how he pedalled his bicycle all over Europe. One summer he and his friend covered over 3500 miles. He had earned part of his way through Oberlin as athletic instructor. All this was evidence of his excellent physique. Soon after I became associated with him (in 1932 he was 64 years of age) we began sending instruments up in airplanes at March Field. These flights went on "round the clock" for three full days. Pilots changed after each of the 5 hour flights but the ground crews continued on. While the plane was gone, the ground crews would sit around and talk instead of getting some sleep. Dr. Millikan, however, would curl up on an old cot in one of the hangers and would be asleep almost immediately. By the end of the third day, the crews were completely worn out, but "The Chief" was as "fresh as a daisy."

Soon after this we went to northern Manitoba, Canada where the Royal Canadian Air Force made some airplane flights for us. Following this we went to $14000 \mathrm{ft}$ Pike's Peak to make some cosmic-ray measurements there. We had along 600 pounds of lead to shield out the local gamma rays. The rock walls of the old building there were quite thick and he insisted on hoisting this lead, which was in six pieces, up on a stool on a table to eliminate shielding of cosmic rays by the rock walls. He was panting by the time we had gotten the lead in place, but I was panting more. That night he slept soundly while I turned and tossed. I had a headache for 3 days due to the altitude. He said he had never had a headache in his life! Some people are just made that way.

In 1939 at the age of 71 when we were making balloon flights at Agra, India, he insisted on riding a bicycle, just as Bill Pickering and I were going to do, from the hotel out to the observatory, which was a distance of two miles. I say, he insisted, but only for a while, for Mrs. Millikan insisted otherwise as soon as she found out about it.

I was always amazed that he could be asleep so soon after going to bed. It is difficult for many of us to close down after a day's work. He somehow had the ability to relax completely, and sleep soundly, even for a short time.

He could be light and cheerful, even in the face of adversity. With all the trials and tribulations he faced at the Institute, especially during the depression years, he was never bitter. He usually saw the bright side and immediately began making plans to get out of a difficulty.

One instance of our troubles occurred at Lake Arrowhead in California, in 1932. Soon after completing our first self-recording ionization chamber we took it to the lake to make some surface measurements. We anchored the row boat, with the instrument inside 600 pounds of lead, out in the middle of the lake and left it 
for the night. In the morning we looked out and saw no boat. We soon found some boards and a notebook along the shore. A squall had come up during the night and our boat and equipment were at the bottom of the lake, under $125 \mathrm{ft}$ of water. We dragged the bottom and pulled up fishing poles, automobile tires and barbed wire fence, but no instrument. Millikan sent a telegram to Arnold at March Field, telling of our hard luck and that we would have to postpone the flights we were scheduled to make there. Arnold sent a wire back, "Serves you right for playing with the Navy."

To give an accurate picture to you of the characteristics of this man in so short a space is almost an impossible job. I. hope that someone will undertake, before too long, a carefully done biography. A short biography appeared in Biographical Memoirs, Volume XXXIII, published for The National Academy of Sciences in 1959 by Columbia University Press. This was written jointly by Dr. Lee A. Dubridge and Dr. Paul S. Epstein. I like a quotation given there. The source is one of Dr. Millikan's associates. He said, "The secret of his success lay to a large extent in the simple virtues instilled in his upbringing. He had a single-minded devotion to all he was doing, and put his work above his personal desires and aspirations. His combination of native good sense and intellectual honesty led him far both in science and in public life. In spite of his success and high public position, he always remained a simple man of true humility. He was not always, technically speaking, a "good administrator," but even this worked to the advantage of Caltech: he never lost sight of the ultimate aims; he was the rare administrator for whom the interest of science came first.

"But, above all, he was a man with a warm heart, a kind benevolent man always eager to be helpful, even at the cost of trouble and inconvenience."

In 1946, at the age of 78 , he handed over the reins, as head of the Institute, to Lee A. Dubridge. He had served ten years past normal mandatory retirement age, at the request of the Board of Trustees. He had run a good race, he now passed on the torch to the younger men.

After his retirement, the Trustees fixed up a room for him in Norman Bridge Laboratory. It combined the two rooms that he and Bowen had used in the earlier years of Bridge Lab. Here he and his faithful secretary, Miss Inga Howard, came each day after his retirement, as regularly as ever. He now had time to write his autobiography. He never grew tired of talking with friends and visitors and he had many callers from various parts of the world.

He had remained interested in cosmic-ray research and could hardly wait until the Second World War was over to get out on another expedition. It took time to get instruments made, but by the summer of 1947 we were ready to make balloon flights with counter telescopes. Starting at San Antonio, Texas we worked north to Saskatoon, Canada, making a series of balloon flights at 7 different latitudes. Dr. Millikan went with us in our Dodge truck and helped with all the flights. He was then 79 .

His energy and endurance amazed us all. This was so intellectually as well as physically. He was a great admirer of Benjamin Franklin and loved to lecture to the sophomores on the contributions Ben Franklin had made to electrostatics. He insisted on doing many of the experiments on electrostatics just as Franklin had done themwith wax, silk thread and the simplest of apparatus. He gave his last lecture to the sophomores in February 1953.

During the last few years of his life, his memory began to fail and he could not recall names. He called it "an old man's memory." I am reminded of a story told by Dr. Klopsteg at a meeting of the American Association of Physics Teachers at St. Olaf College several years ago. Some who are here today will remember how he reminisced about the early days of this society. One of his stories told at that lecture ran as follows: A psychologist was giving a lecture on senility. At one point of his address, he said there were three ways one could tell whether he was becoming senile. Number one was, you began to forget names. Number two was, you began to forget faces. And number three was, . . . Dr. Millikan attended the Commencement exercises at Caltech of June of 1953. His walk was much less springy than it had been a few months before and he needed help to negotiate the several steps. During the summer he failed rapidly. He died at the Huntington Memorial Hospital in Pasa- 
dena on 19 December 1953, three months before he would have arrived at the age of 86 .

And so passed a remarkable character. It was said that there would never be another like him, that after he was made the mold broke. He had no choice concerning the unique genes with which he was born. But he always insisted that one did have the power of making choices which had to be exercised to determine the way one wanted to go.

I should like to end this brief sketch of Millikan's life as DuBridge and Epstein ended their brief biographical memoir in the following way. "In short," they said, "he combined a rare insight into science with a rare understanding of human beings."

\title{
A Laboratory Demonstration of the Equivalence of Potential Energy and Work
}

\author{
Otto Henry Zinke \\ University of Arkansas, Fayetteville, Arkansas \\ (Received 17 February 1964)
}

\begin{abstract}
A laboratory experiment is described which demonstrates the equivalence of potential energy and work to an accuracy of several per cent through the use of two magnets.
\end{abstract}

$\mathrm{T}$

HE early introduction of energy conservation laws in elementary physics courses greatly aids the student in the solution of motion equations. The acceptance of the principle of energy conservation is necessary for any introduction of an elementary student to modern physics. It is therefore surprising that a scan of several elementary physics laboratory manuals reveals no experiment which convincingly demonstrates the equivalence of work and the derived expressions of potential and kinetic energy. Air-puck experiments can be expected to demonstrate the equivalence of work and kinetic energy. A simple and inexpensive (if the cost of a cathetometer is not included) experiment to demonstrate the equ.valence of work and gravitational potential energy has been carried out in elementary honorsphysics laboratory at the University of Arkansas with surprisingly accurate and reproducible results.

The equipment consists of a cathetometer, two permanently magnetized ferrite cylinders, a glass tube, and about eight $5 \mathrm{~g}$ masses of the type used with laboratory balances. Each magnet $^{1}$ is approximately $0.9 \mathrm{~cm}$ long and 0.9 $\mathrm{cm}$ in diameter and has a mass of about $3 \mathrm{~g}$. The glass tube has a $1-\mathrm{cm}$ inside diameter and is

\footnotetext{
${ }_{1}$ Can be obtained from National Moldite Company, Inc., 250 South Street, Newark, New Jersey.
}

$10 \mathrm{~cm}$ long. The $5 \mathrm{~g}$ masses are about $0.9 \mathrm{~cm}$ in diameter and $1.3 \mathrm{~cm}$ in total length. The experiment is divided into two parts which are schematized in Fig. 1. In Part (A) the magnets $M_{1}$ and $M_{2}$ are placed in the glass tube with like poles facing each other. The displacement $D$ is measured as a function of the number of the $5 \mathrm{~g}$ masses which are successively dropped down the glass tube on the upper ferrite magnet. These displacements are plotted on graph paper as the abscissa and the successive gravitational forces on the upper magnet are calculated and plotted on the ordinate. Typical data are shown in the solid curve of Fig. 2. It is found that if these

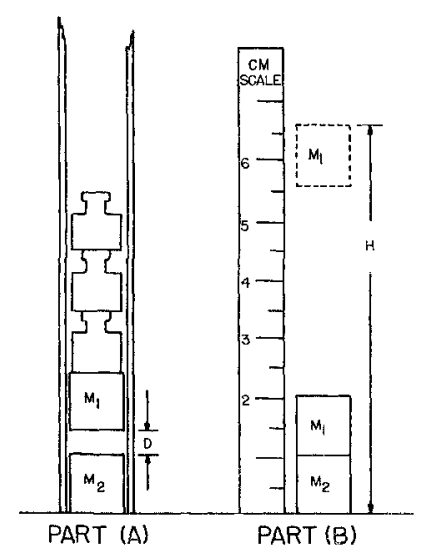

FIG. 1. Diagram of the two parts of the experiment demonstrating equivalence of potential energy and work. 